Check for updates

Cite this: RSC Adv., 2019, 9, 30012

Received 5th August 2019

Accepted 15th September 2019

DOI: $10.1039 / c 9 r a 06087 a$

rsc.li/rsc-advances

\section{Perdecanoic acid as a safe and stable medium- chain peracid for Baeyer-Villiger oxidation of cyclic ketones to lactones $\uparrow$}

\author{
Magdalena Sitko, ${ }^{a}$ Anna Szelwicka, ${ }^{a}$ Andrzej Wojewódka, ${ }^{b}$ Andrzej Skwarek, ${ }^{c}$ \\ Dariusz Tadasiewicz, ${ }^{C}$ Lech Schimmelpfennig, ${ }^{C}$ Krzysztof Dziuba, ${ }^{C}$ \\ Magdalena Morawiec-Witczak ${ }^{c}$ and Anna Chrobok (DD *a
}

\begin{abstract}
Stability studies dedicated to high-energy compounds for a series of linear peracids $\left(\mathrm{C}_{6}-\mathrm{C}_{12}\right)$, including sensitivity to mechanical impulse (shock and friction), as well as electrical (spark) and thermal sensitivity (temperature and heat of decomposition), were presented in this work for the first time. Studies revealed that all peracids were insensitive to shock, while in the case of the other sensitivity tests sharp differences between results for $C_{8}$ and $C_{10}$ peracids were observed. Taking into account the relatively high initial temperature of decomposition (above $64{ }^{\circ} \mathrm{C}$ ) perdecanoic acid was selected as a safe alternative to commonly used hazardous short-chain peracids. Next, a new method for the BaeyerVilliger oxidation was presented. Oxidation of 2 -adamantanone was chosen as a model reaction. Peroctanoic, perdecanoic and perdodecanoic acids were tested as oxidants. Peroctanoic acid was the most reactive but taking into account both safety and kinetic issues, perdecanoic acid was selected for the further studies. The influence of reaction conditions on reaction rate was investigated. Optimized reaction conditions were suggested (two-fold molar excess of peracid with respect to the ketone, toluene as a solvent, $35^{\circ} \mathrm{C}$ ). This exploratory study offers promise with regard to the development of safer alternatives to peracetic acid in industrial oxidation.
\end{abstract}

\section{Introduction}

Peracids are characterized by high oxidation potential and therefore are very reactive oxidizing species. The peroxy bond is weak and can be cleaved readily which results in low stability of peracids. Peracids can decompose spontaneously and explosively under thermal or mechanical stress (shock, impact, friction), and can undergo uncontrolled decomposition which can be catalysed by organic or metal compounds. ${ }^{1,2}$ Therefore, peracids are treated as explosive materials and are covered by special regulations for shipping and storage. ${ }^{1}$ Stabilising compounds (metal salts and chelating agents) are very often added to increase the storage ability of the peracid. ${ }^{3}$

${ }^{a}$ Department of Chemical Organic Technology and Petrochemistry, Silesian University of Technology, Krzywoustego 4, 44-100 Gliwice, Poland. E-mail: Anna.Chrobok@polsl. $p l$

${ }^{b}$ Department of Inorganic Chemistry, Analytical Chemistry and Electrochemistry, Silesian University of Technology, Krzywoustego 6, 44-100 Gliwice, Poland

${ }^{c}$ Grupa Azoty Zaklady Azotowe Puławy S.A., Tysiaclecia Państwa Polskiego 13, 24-110 Putawy, Poland

$\dagger$ Electronic supplementary information (ESI) available: Elemental analysis, ${ }^{1} \mathrm{H}$ and ${ }^{13} \mathrm{C}$ NMR spectra of peracids, detailed data concerning peracids sensitivities to friction, shock, electric spark, and thermal stability of peracids. See DOI: $10.1039 / \mathrm{c} 9 \mathrm{ra} 06087 \mathrm{a}$
The shorter the alkyl chain the more unstable the peracid is. This is the result of higher percentage share of active oxygen in the molar mass of peracid. The average dissociation energy of the peroxy bond of peracids is low ( $c a .90 \mathrm{~kJ} \mathrm{~mol}^{-1}$ ) which causes the lowest stability in the group of organic peroxides. Perbenzoic acid caused skin tumors in mice but it is safer than peracetic or performic acid. ${ }^{3}$ However, there are no appropriate results for safety measures for this species. Short-chain aliphatic peracids are miscible with water while the longerchain $\left(\mathrm{C}_{6}\right.$ and higher $)$ are not. As a result short-chain peracids exhibited low toxicity on animals and longer-chain are non-toxic and non-irritant. A series of tests are performed to assess the hazard with handling of peracids, such as detonation ability, shock, heat and friction sensitivity. The most popular peracids are the short-chain and the hazard with handling with these hazardous materials limits their commercial application. For example, the transport and storage of peracetic acid is prohibited. ${ }^{2,4,5}$

In industrial practice performic or peracetic acid are very often generated in situ from adequate carboxylic acid or aldehyde to increase process safety. Peracids are the commonlyapplied oxidizing agents, used also in a standard protocol for Baeyer-Villiger oxidation of ketones to lactones. ${ }^{6}$ Lactones are fine chemical products with many potential applications, e.g. in polymers, pharmaceuticals and agrochemicals industry. ${ }^{7-9}$ 
The production of the most important lactones in the industry is still based on peracid acid, e.g. the production of useful monomer $\varepsilon$-caprolactone (world production 40-60 KTA). $\varepsilon$-Caprolactone is manufactured by the oxidation of cyclohexanone with peracetic acid (Perstorp AB). ${ }^{10}$ The reaction is carried out in two reactors: first is used for peracetic acid synthesis and in the second one the oxidation of cyclohexanone is carried out. Alternatively, BASF produces $\varepsilon$-caprolactone by the oxidation of cyclohexanone with peracetic acid generated in situ by the aerobic oxidation of acetaldehyde in the same reactor to avoid problems with peracetic acid safety issue. ${ }^{11}$

The use of medium chain peracid (the most often used perC $_{8}$ ) is known from chemo-enzymatic Baeyer-Villiger oxidation. In this variant, the carboxylic acid is oxidized to peracid in situ in the presence of lipase B Candida antarctica and next the freshly generated peracid oxidizes ketone to lactone. ${ }^{\mathbf{1 2 , 1 3}}$

The only literature data concerning the application and stability studies of longer chain peracids is the application of dodecanebis(peroxoic acid) in the selective oxidation of aliphatic amines to oxime or bromination of aminoanthracene9,10-dione. ${ }^{\mathbf{1 4 , 1 5}}$ Nevertheless, high stability at room temperature and non-shock sensitive in nature was confirmed only with DSC.

Herein, we present for the first time stability tests for medium-chain aliphatic peracids $\left(\mathrm{C}_{6}-\mathrm{C}_{12}\right)$ which can be the safe alternative to very reactive short-chain analogues. Furthermore, the goal of this work was to design an innovative, safe process for the synthesis of lactones in Baeyer-Villiger oxidation based on extremely stable perdecanoic acid as oxidant. The studies emerged the "forgotten oxidants" as very reactive but still safe oxidants. Replacing of short-chain peracids with less hazardous medium-chain peracids may lead to an economically viable process in the industry. Moreover, application of oxidant analogue, which minimize the potential for chemical accidents, including explosions, is in compliance with the idea of green chemistry.

\section{Experimental}

\section{Materials and methods}

Ketones, hexanoic, octanoic, decanoic and dodecanoic acids were purchased from Sigma-Aldrich. Toluene, dichloromethane, acetonitrile, glacial acetic acid and $\mathrm{H}_{2} \mathrm{SO}_{4} 95$ wt\% were purchased from Chempur, while aqueous $50 \mathrm{wt} \% \mathrm{H}_{2} \mathrm{O}_{2}$ solution in water, $0.1 \mathrm{M}$ aqueous solution of sodium thiosulphate and sodium iodide were purchased from Avantor Performance Materials.

GC analyses were performed using a PerkinElmer Clarus 500 equipped with an $\mathrm{SPB}^{\mathrm{TM}}-5$ column $(30 \mathrm{~m} \times 0.2 \mathrm{~mm} \times 0.2 \mu \mathrm{m}$ film) and a flame ionization detector (FID). Yields were determined based on calibration curves; $n$-decane was used as an internal standard.

Melting points of peracids were determined using EZ-Melt apparatus (maximum temperature range: 20-400 ${ }^{\circ} \mathrm{C}$ ). Measurements were performed in a capillary using $5 \mathrm{mg}$ of each sample. Temperature range were set as $28-65^{\circ} \mathrm{C}$ in heating rate of $0.5{ }^{\circ} \mathrm{C} \mathrm{min}^{-1}$.
${ }^{1} \mathrm{H}$ NMR spectra were recorded at $600 \mathrm{MHz}$, and ${ }^{13} \mathrm{C} \mathrm{NMR}$ spectra were recorded at $150 \mathrm{MHz}$ using a Varian system. Samples were analysed in the form of solutions in $\mathrm{CDCl}_{3}$ and TMS was used as an internal reference $(\delta=0 \mathrm{ppm})$.

The determination of carbon, hydrogen and nitrogen content in peracid molecules was carried out based on elemental analysis using Vario MICRO cube automatic analyser. For each peracid the analysis was performed three times using samples of approximately $3 \mathrm{mg}$.

Purity of peroxyacids, as well as the content of peroxy groups in the post-reaction mixtures were determined by iodometric titration. A weighted sample (ca. 0.100-0.200 g) and $20 \mathrm{~mL}$ of glacial acetic acid were introduced to the $250 \mathrm{~mL}$-Erlenmeyer flask. The flask was purged with argon for 25 seconds and a pinch of sodium iodide was added. After closing, the flask was placed in the dark for 30 minutes. Then $20 \mathrm{~mL}$ of distilled water and 5 drops of starch were added and the mixture was titrated by the $0.1 \mathrm{M}$ aqueous solution of sodium thiosulphate. A molar content of peroxy groups was calculated according to an equation $n=0.5 c V_{\mathrm{T}}$ [mol], where: 0.5 - coefficient calculated based on the stoichiometry of the reactions $2 \mathrm{I}^{-}+3 \mathrm{H}^{+}+\mathrm{OOH}^{-} \rightarrow \mathrm{I}_{2}+$ $2 \mathrm{H}_{2} \mathrm{O}$ and $\mathrm{I}_{2}+2 \mathrm{~S}_{2} \mathrm{O}_{3}{ }^{2-} \rightarrow \mathrm{S}_{4} \mathrm{O}_{6}{ }^{2-}+2 \mathrm{I}^{-}, c-$ molar concentration of the titrant $\left[\mathrm{mol} \mathrm{L}^{-1}\right], V_{\mathrm{T}}$ - volume of the titrant $[\mathrm{L}]$.

The test for peracids shock sensitivity was carried out according to the PN-EN 13631-4 standard using the BAM apparatus equipped with 3 different weights: 1,5 , and $10 \mathrm{~kg}$. A sample of the tested peracid was placed in the shock set. This set was then placed centrally on the anvil and the specific weight was installed at the height, that corresponds to its appropriate potential energy. The weight was then released and it was observed whether there was any reaction (sound effects, flame). The test was continued until no reaction occurred in 6 consecutive trials for a specific energy value.

The test for peracids friction sensitivity was carried out according to the PN-EN 13631-3 standard using the Peters apparatus, determining the upper limit of insensitivity, the lower limit of sensitivity, and the value of E50 (energy under which the tested substance is initiated with $50 \%$ probability). The test was carried out by placing a small sample of peroxyacid on a porcelain plate, then the plate was placed in the apparatus, and a stamp was placed at one end of the sample. During the test the sample was moving under the stamp and it was observed whether there was any reaction (bang, crack, flame, visible mark on the plate). The test was started with the force of $360 \mathrm{~N}$ and continued until no reaction occurred in 6 consecutive trials for a specific force value.

The test for peracids electric spark sensitivity was carried out using the apparatus consists of a source of a constant voltage, a system of capacitors, and two special electrodes. The capacitors of an adequate capacity were selected for the tests, and their connection method and voltage values were changed to achieve specific energy of the electric spark. The sample of tested peroxyacid was placed in a special metal mold and covered with a foil disc with an opening for the electrode needle. The sample was placed on the bottom electrode, then the electrodes were brought so close that the needle of the positive (top) electrode touched the foil disc. When the energy value was selected, the 
capacitors were charged and the test was started, which caused a flashover between the electrodes. It was observed whether a reaction occurred (presence of smoke, smell of burning, or smudging of the mass of the sample). The test was continued until no reaction occurred in 6 consecutive trials for a specific energy value.

Thermal stability of peracids was determined by the differential scanning calorimetry method (DSC) using the MettlerToledo DSC 822e differential scanning calorimeter. Samples of approximately $3 \mathrm{mg}$ were heated from $-65{ }^{\circ} \mathrm{C}$ to $150{ }^{\circ} \mathrm{C}$ in a nitrogen atmosphere with a flow rate of $60 \mathrm{~mL} \min ^{-1}$ at a heating rate of 2,5 , and $10{ }^{\circ} \mathrm{C} \min ^{-1}$.

\section{Synthetic procedures}

General procedure for the synthesis of peracids. Perhexanoic, peroctanoic, perdecanoic, and perdodecanoic acids were synthesized based on the procedure described in the literature. $^{\mathbf{1 6}}$

Carboxylic acid $(20.0 \mathrm{~g}, 0.10-0.17 \mathrm{~mol})$ dissolved in $95 \mathrm{wt} \%$ sulphuric acid $(40.0 \mathrm{~g})$ was introduced into a high $250 \mathrm{~mL}$ beaker, equipped with a mechanic stirrer and placed in ice-bath to cool $\left(10{ }^{\circ} \mathrm{C}\right)$. After stabilization of the temperature, the $50 \mathrm{wt} \%$ aqueous solution of hydrogen peroxide (1.5 eq.) was carefully dropwised for $10 \mathrm{~min}$, taking care to not exceed the temperature of the mixture above $30{ }^{\circ} \mathrm{C}$. After addition of the oxidant, the mixture was stirred at $1000 \mathrm{rpm}$ for $50 \mathrm{~min}$. Next, ice water ( $c a .150 \mathrm{~mL}$ ) was slowly added to the beaker, and peracid crystallized as a white solid. The content of the beaker was transferred to a separating funnel and extracted with diethyl ether $(5 \times 30 \mathrm{~mL})$. The organic phase was washed with water $(20 \mathrm{~mL})$ and dried over anhydrous $\mathrm{MgSO}_{4}$. After filtration, the filtrate was carefully evaporated on a vacuum rotary evaporator at $25{ }^{\circ} \mathrm{C}$. Crude peracid was recrystallized from petroleum ether $(10 \mathrm{~mL} / 1 \mathrm{~g}$ of the peracid $)$ at $-20{ }^{\circ} \mathrm{C}\left(-30{ }^{\circ} \mathrm{C}\right.$ for perhexanoic acid). The product was then filtered off under vacuum and washed with a cold petroleum ether $(10 \mathrm{~mL})$. The yields of peracids were in the range of $90-95 \%$, except of perhexanoic acid $(75 \%)$.

Peroctanoic acid. ${ }^{1} \mathrm{H}$ NMR (600 $\left.\mathrm{MHz}, \mathrm{CDCl}_{3}, \mathrm{TMS}\right): \delta / \mathrm{ppm}$ 0.85-0.95 (m, 3H), 1.24-1.39 (m, 8H), $1.72(\mathrm{dt}, J=15.0 \mathrm{~Hz}, J=$ $7.5 \mathrm{~Hz}, 2 \mathrm{H}), 2.43(\mathrm{dd}, J=8.7 \mathrm{~Hz}, J=6.3 \mathrm{~Hz}, 2 \mathrm{H}), 11.36(\mathrm{~s}, 1 \mathrm{H})$. ${ }^{13} \mathrm{C}$ NMR (600 MHz, $\left.\mathrm{CDCl}_{3}, \mathrm{TMS}\right): \delta / \mathrm{ppm} 14.17,22.70,24.79$, 28.87, 29.04, 30.58, 31.69, 174.83.

Perdecanoic acid. ${ }^{1} \mathrm{H}$ NMR (600 $\left.\mathrm{MHz}, \mathrm{CDCl}_{3}, \mathrm{TMS}\right): \delta / \mathrm{ppm}$ $0.88(\mathrm{t}, J=6.8 \mathrm{~Hz}, 3 \mathrm{H}), 1.18-1.40(\mathrm{~m}, 12 \mathrm{H}), 1.61-1.76(\mathrm{~m}, 2 \mathrm{H})$, $2.41(\mathrm{t}, J=7.5 \mathrm{~Hz}, 2 \mathrm{H}), 11.36(\mathrm{~s}, 1 \mathrm{H}) .{ }^{13} \mathrm{C} \mathrm{NMR}\left(600 \mathrm{MHz}, \mathrm{CDCl}_{3}\right.$, TMS): $\delta / p p m ~ 14.23,22.80,24.79,29.08,29.20,29.35,29.46$, 30.58, 31.98, 174.82 .

Perdodecanoic acid. ${ }^{1} \mathrm{H}$ NMR (600 $\left.\mathrm{MHz}, \mathrm{CDCl}_{3}, \mathrm{TMS}\right): \delta / \mathrm{ppm}$ $0.88(\mathrm{t}, J=6.8 \mathrm{~Hz}, 3 \mathrm{H}), 1.19-1.39(\mathrm{~m}, 16 \mathrm{H}), 1.64-1.75(\mathrm{~m}, 2 \mathrm{H})$, $2.41(\mathrm{t}, J=7.5 \mathrm{~Hz}, 2 \mathrm{H}), 11.36(\mathrm{~s}, 1 \mathrm{H}) .{ }^{13} \mathrm{C} \mathrm{NMR}\left(600 \mathrm{MHz}, \mathrm{CDCl}_{3}\right.$, TMS): $\delta / p p m ~ 14.25,22.84,24.79,29.09,29.21,29.47,29.50$, 29.69, 29.73, 30.58, 32.05, 174.83 .

General procedure for the Baeyer-Villiger oxidation of cyclic ketones in the presence of synthesized peracids. A ketone $(0.67$ $\mathrm{mmol}$ ) was introduced into a two-neck $10 \mathrm{~mL}$ round-bottom flask, to which toluene $(2 \mathrm{~mL})$ and $n$-decane $(0.10 \mathrm{mmol}$, external standard) were added. Then, peracid $(1.34 \mathrm{mmol})$ was added. The flask was equipped with a reflux condenser, sealed with a septum and then mixed on magnetic stirrer at $25-45{ }^{\circ} \mathrm{C}$ for 10-120 $\mathrm{min}$ (1200 $\mathrm{rpm}$ ), depending on the reaction rate. Periodically, during the reaction, $10 \mu \mathrm{L}$ of the samples diluted with dichloromethane were collected to monitor the progress of the reaction using GC. The yields of the lactone were in the range $96-99 \%$.

\section{Results and discussion}

\section{Stability tests}

In order to study the stability of medium chain peracids, four selected peracids of an even number of carbon atoms $\left(\mathrm{C}_{6}-\mathrm{C}_{12}\right)$ were synthesized according to the procedure described in the literature. ${ }^{16}$ In the reaction of aliphatic acids with $50 \mathrm{wt} \%$ aqueous solution of $\mathrm{H}_{2} \mathrm{O}_{2}$ in the presence of $95 \mathrm{wt} \%$ of $\mathrm{H}_{2} \mathrm{SO}_{4}$ as catalyst and reaction medium the peracids were synthesized with high yields (90-95\%) and purities (100\%). The only exception was perhexanoic acid which was obtained as $86 \mathrm{wt} \%$ solution in hexanoic acid with $75 \%$ yield. Unfortunately, after two weeks of storage in $20{ }^{\circ} \mathrm{C}$ the decomposition of perhexanoic acid was observed up to $55 \mathrm{wt} \%$ (Table 1). The structure and purity of peracids were confirmed with ${ }^{1} \mathrm{H}$ and ${ }^{13} \mathrm{C}$ NMR (Fig. S1-S6†) as well as elemental analysis (Table $\mathrm{S} 1 \dagger$ ).

Next, peracids were studied in a series of special tests dedicated for high-energy compounds, including sensitivity to mechanical impulse (shock and friction), as well as electrical (spark) and thermal sensitivity (temperature and heat of decomposition).

The test for sensitivity of peracids to friction was based on the observation of the effects of an explosive reaction (or lack thereof) of the sample exposed to friction of a specific force (Fig. S7, Tables S2-S5 $\dagger$ ). The test determining sensitivity of peracids to shock was based on the observation of the effects of an explosive reaction (or lack thereof) of the sample, which was exposed to shock of a specific energy (Tables S6-S9†). The sensitivity of peracids to the electric spark was determined based on the observation of the effects of an explosive reaction (or lack thereof) of the sample, which was exposed to an electric spark of a specific energy (Tables S10-S12 $\dagger$ ). For all types of tests both sensitivity and insensitivity limits were determined, as samples were tested first increasing and then decreasing the intensity of each stimulus (Table 2).

Table 1 Characteristics of synthesized peracids

\begin{tabular}{lll}
\hline Peracid & Melting point $\left({ }^{\circ} \mathrm{C}\right)$ & Purity $^{a}($ wt $\%)$ \\
\hline $\mathrm{C}_{5} \mathrm{H}_{11} \mathrm{COOOH}\left(\right.$ perC $\left._{6}\right)$ & $<\mathrm{RT}$ & $86^{b} / 55^{c}$ \\
$\mathrm{C}_{7} \mathrm{H}_{15} \mathrm{COOOH}\left(\operatorname{perC}_{8}\right)$ & $31.5-32.6$ & 100 \\
$\mathrm{C}_{9} \mathrm{H}_{19} \mathrm{COOOH}\left(\operatorname{perC}_{10}\right)$ & $42.7-43.3$ & 100 \\
$\mathrm{C}_{11} \mathrm{H}_{23} \mathrm{COOOH}\left(\operatorname{perC}_{12}\right)$ & $49.5-50.5$ & 100
\end{tabular}

${ }^{a}$ Calculated based on the iodometric titration. ${ }^{b}$ Just after synthesis. ${ }^{c}$ After 2 weeks of storage at $-20{ }^{\circ} \mathrm{C}$, prior to stability analysis. 
Table 2 Sensitivities of peracids to shock, friction, and electric spark

\begin{tabular}{|c|c|c|c|c|c|c|}
\hline \multirow[b]{2}{*}{ Peracid } & \multicolumn{2}{|c|}{ Shock, energy/J } & \multicolumn{2}{|c|}{ Friction, force/N } & \multicolumn{2}{|c|}{ Electric spark, energy/J } \\
\hline & $\begin{array}{l}\text { Sensitivity } \\
\text { limit }\end{array}$ & $\begin{array}{l}\text { Insensitivity } \\
\text { limit }\end{array}$ & $\begin{array}{l}\text { Sensitivity } \\
\text { limit }\end{array}$ & $\begin{array}{l}\text { Insensitivity } \\
\text { limit }\end{array}$ & $\begin{array}{l}\text { Sensitivity } \\
\text { limit }\end{array}$ & $\begin{array}{l}\text { Insensitivity } \\
\text { limit }\end{array}$ \\
\hline perC $_{6}$ & $\mathrm{n} / \mathrm{a}$ & $>50$ & 47 & 41 & - & - \\
\hline perC $_{8}$ & $\mathrm{n} / \mathrm{a}$ & $>50$ & 64 & 60 & 0.62 & 0.56 \\
\hline perC $_{10}$ & $\mathrm{n} / \mathrm{a}$ & $>50$ & 110 & 106 & 13.50 & 12.62 \\
\hline perC $_{12}$ & $\mathrm{n} / \mathrm{a}$ & $>50$ & 118 & 110 & 12.62 & 11.76 \\
\hline
\end{tabular}

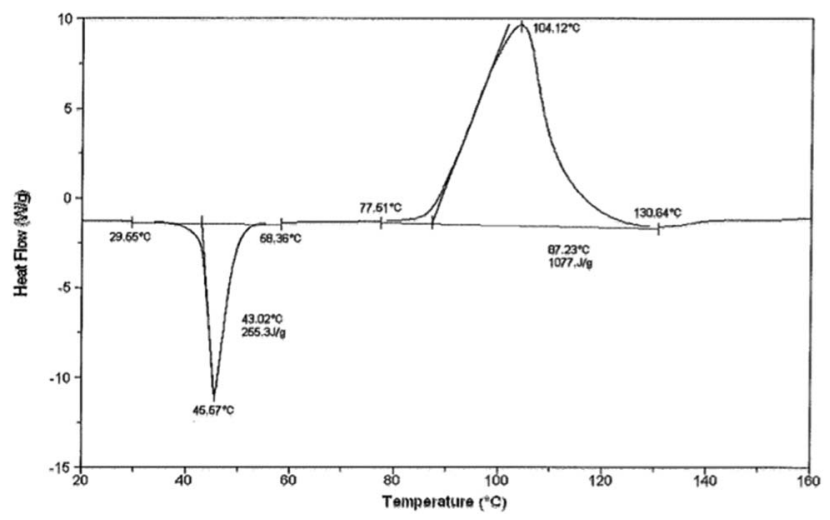

Fig. 1 DSC of perdecanoic acid at a heating rate of $10{ }^{\circ} \mathrm{C} \mathrm{min}^{-1}$.

According to the tests, all peracids are insensitive to shock energy of $50 \mathrm{~J}$, which is the insensitivity limit for the high-energy compounds. They are therefore resistant to this type of impulse. The results showed that peroctanoic acid has a significantly lower limits for sensitivities to friction and electric spark than peracids with longer alkyl chain. In the case of friction the limit is over two times lower, while for electric spark it is over twenty times lower than for $\mathrm{C}_{10}$ and $\mathrm{C}_{12}$ peracids.

Interestingly, perdecanoic and perdodecanoic acids are characterized by almost the same sensitivity limits for the tested types of stimulus. Due to technical limitations determination of sensitivity of perhexanoic acid to electric spark was not possible; however, taking into account friction sensitivity as well as decomposition during storage, this peracid cannot be considered as a safe compound, and was eliminated on this stage of studies.

Table 3 Thermal stability of peracids (recorded for the heating rate $5^{\circ} \mathrm{C} \mathrm{min}^{-1}$ )

\begin{tabular}{lcrl}
\hline & & & \multicolumn{1}{l}{ Heat of decomposition/kJ } \\
Peracid & $T_{\text {initial }} /{ }^{\circ} \mathrm{C}$ & $T_{\text {max }} /{ }^{\circ} \mathrm{C}$ & $\mathrm{kg}^{-1}$ \\
\hline perC $_{8}$ & 69.7 & 92.2 & 314 \\
perC $_{10}$ & 64.2 & 96.2 & 1036 \\
perC $_{12}$ & 68.7 & 109.0 & 734 \\
$50 \mathrm{wt} \%$ aq. $\operatorname{perC}_{2}{ }^{a, 17}$ & 38.1 & 62.0 & 1503 \\
${ }^{a}$ Heating rate $4{ }^{\circ} \mathrm{C} \mathrm{\text {min } ^ { - 1 } .}$ & &
\end{tabular}

Thermal behavior of peroctanoic, perdecanoic and perdodecanoic acids was also tested, based on differential scanning calorimetry (DSC) measurements. The results were depended on the heating rate (Table S13 $\dagger$ ), but generally the thermograms revealed narrow and sharp peaks of melting process with relatively regular heat, followed by broad peaks of decomposition with irregular heat (Fig. 1).

The temperature of decomposition of tested peracids increased proportionally to their molar mass, and they decomposed slowly at relatively high temperature (initial temperature $64-70{ }^{\circ} \mathrm{C}$, maximum temperature $92-109{ }^{\circ} \mathrm{C}$ ). A large amount of heat was released during decomposition, the highest for perdecanoic acid (more than $1000 \mathrm{~kJ} \mathrm{~kg}^{-1}$, Table 3). Comparing to the literature data for $50 \mathrm{wt} \%$ aqueous solution of peracetic acid, ${ }^{17}$ both lower temperatures and higher heat of decomposition illustrate the dangerous nature of peracetic acid. The longer alkyl chain in peracid the higher stability and usability in practice, e.g. as oxidation agent. Based on these results the perdecanoic acid is the most promising for the application as safe oxidant in chemical reactions from the process safety point of view.

\section{Baeyer-Villiger oxidation with peracids as oxidants}

In order to demonstrate the reactivity of longer alkyl chain peracids the Baeyer-Villiger oxidation of cyclic ketones to lactones was chosen as a model reaction. For initial studies the oxidation of 2-adamantanone was tested (Scheme 1) started with 2-fold molar excess of peracid as oxidation agent. The reaction was carried out at ambient temperature and toluene was used as a solvent.

The longer the alkyl chain in peracid the lower reactivity was observed which is related to a decrease of percentage share of active oxygen in the oxidant molecule. For peroctanoic acid the reaction was completed after $40 \mathrm{~min}$, while in the case of perdodecanoic only $70 \%$ of lactone yield was obtained in the same

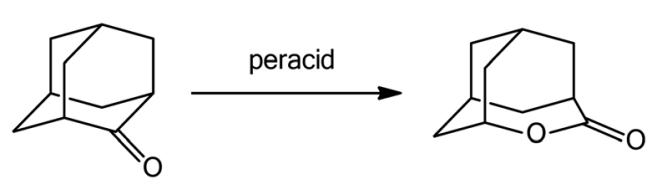

Scheme 1 Model Baeyer-Villiger oxidation of 2-adamantanone to 4oxatricyclo[4.3.1.1 $1^{3,8}$ ] undecan-5-one. 


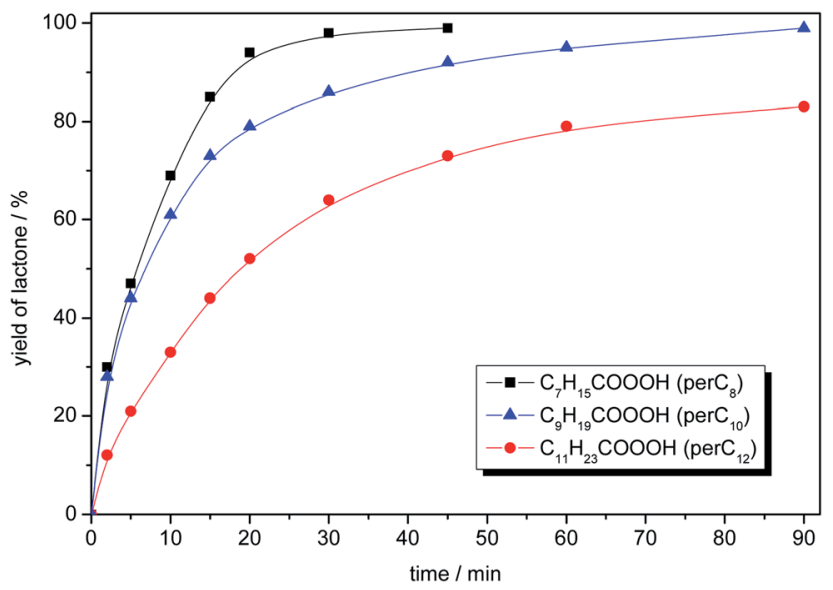

Fig. 2 The activity of peracids in the model oxidation of 2-adamantanone. Reaction conditions: 2-adamantanone $(0.100 \mathrm{~g}, 0.67$ $\mathrm{mmol})$, peracid $(1.34 \mathrm{mmol})$, toluene $(2 \mathrm{~mL}), 25^{\circ} \mathrm{C}, 1200 \mathrm{rpm}$.

time. Taking into account both safety and kinetic issues, perdecanoic acid was selected to the further studies (Fig. 2).

Additionally, the influence of various solvents (dichloromethane, toluene and acetonitrile) for model reaction was examined (Fig. 3). Lactone was obtained almost quantitatively in $60 \mathrm{~min}$ at ambient temperature in each case, but the highest initial reaction rate was observed when dichloromethane was applied. However, because of environmental issues, toluene is preferred.

Temperature of the oxidation process had a significant influence on the reaction rate (Fig. 4). The reactions were carried out at $25,35,45$ and $55^{\circ} \mathrm{C}$. High reaction rate, low residence time creates possibility in the future to use continuous flow reactor, instead of batch approach, what is of significant importance for industrial scale production.

In the next step molar ratio of the oxidant to the ketone was studied (Fig. 5). The conversion of ketone to lactone was almost full in 30 minutes at $35{ }^{\circ} \mathrm{C}$ for the three- and two-fold molar

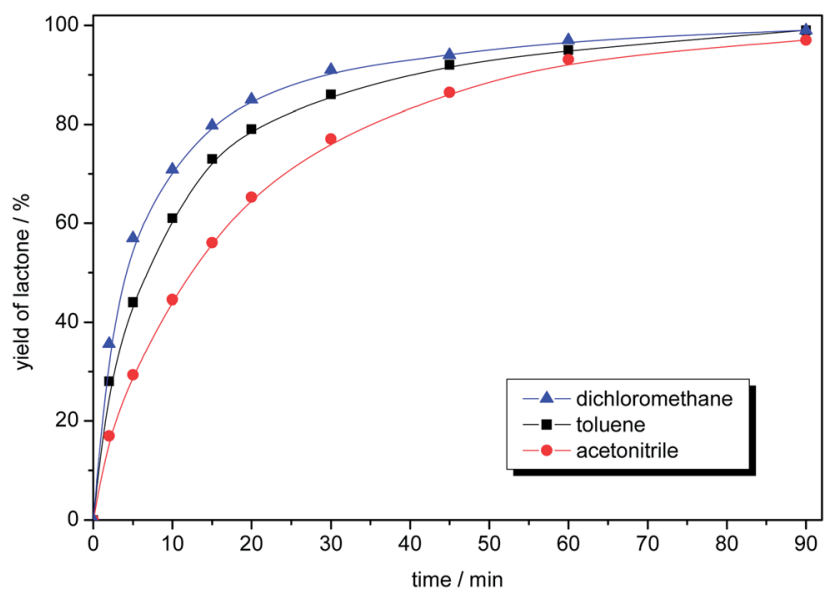

Fig. 3 The influence of the solvent for the model oxidation of 2 adamantanone. Reaction conditions: 2-adamantanone $(0.100 \mathrm{~g}, 0.67$ $\mathrm{mmol})$, perdecanoic acid (1.34 mmol), solvent $(2 \mathrm{~mL}), 25^{\circ} \mathrm{C}, 1200 \mathrm{rpm}$.

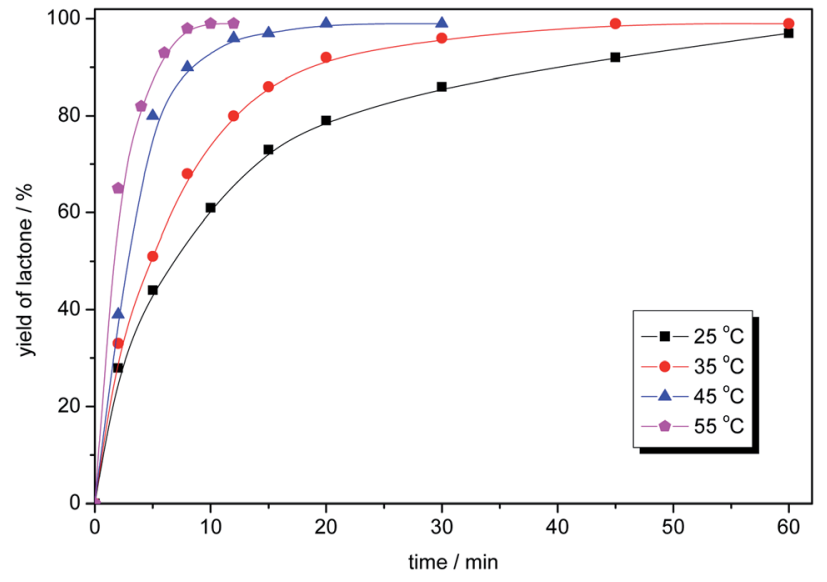

Fig. 4 The influence of the temperature for the model oxidation of 2adamantanone. Reaction conditions: 2-adamantanone $(0.100 \mathrm{~g}, 0.67$ $\mathrm{mmol})$, perdecanoic acid (1.34 mmol), toluene $(2 \mathrm{~mL}), 1200 \mathrm{rpm}$.

excess of perdecanoic acid in respect to the ketone. Lower amounts of oxidant caused a visible decrease of the reaction rate, and only $86 \%$ (1.5 eq. of peracid) and $79 \%$ (equimolar amount) yields of lactone were obtained in 30 minutes.

Besides the reaction rate, the safety issues and the easy work up are also the key factors which influence the economic aspects. The concentration of peracid in the post-reaction mixture should be taken into the consideration. Due to the safety reasons peroxy groups must be removed from the postreaction mixture prior to separation of the product. The concentrations of peracid before and after the oxidation of ketone, depending on a molar ratio of ketone to peracid in various temperatures were studied (Table 4). The higher concentration of peracid led to the faster reaction but the content of unreacted peroxy group also increased. The application of molar ratio higher than $1: 2$ (ketone : peracid) is unreasonable. For the experiments using a fixed two-fold molar

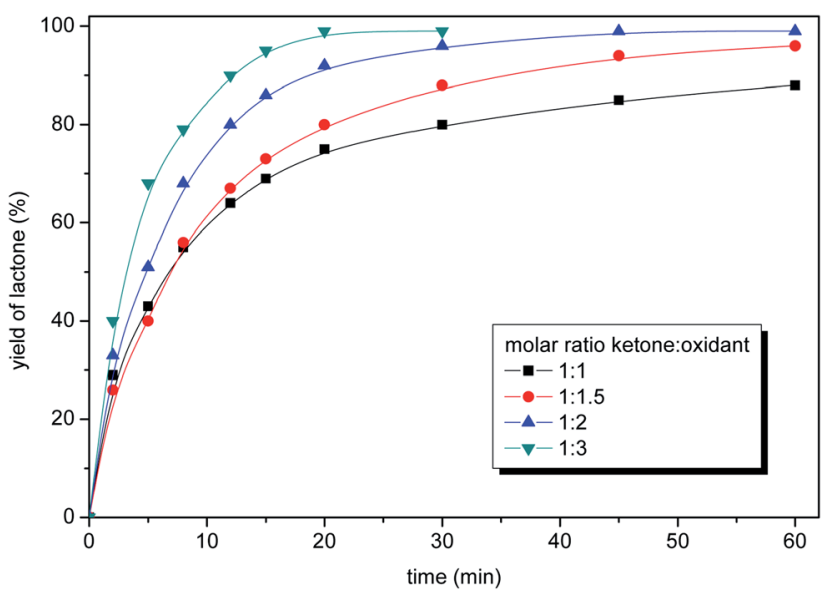

Fig. 5 The influence of molar ratio ketone: oxidant for the model oxidation of 2-adamantanone. Reaction conditions: 2-adamantanone $(0.100 \mathrm{~g}, 0.67 \mathrm{mmol})$, perdecanoic acid, toluene $(2 \mathrm{~mL}), 35{ }^{\circ} \mathrm{C}$, $1200 \mathrm{rpm}$. 
Table 4 The concentration of peroxy group before reaction $\left(C_{0}\right)$ and in the post-reaction mixture $\left(C_{1}\right)$ for the model oxidation of 2adamantanone

\begin{tabular}{|c|c|c|c|c|c|}
\hline Molar ratio ketone : peracid & Temp. $/{ }^{\circ} \mathrm{C}$ & $C_{0} / \mathrm{wt} \%$ & Time/min & Yield of lactone/\% & $C_{1} / \mathrm{wt} \%$ \\
\hline $1: 1$ & 35 & 6.6 & 60 & 88 & 0.7 \\
\hline $1: 1.5$ & 35 & 9.8 & 60 & 96 & 3.2 \\
\hline $1: 3$ & 35 & 17.5 & 30 & 99 & 12.3 \\
\hline $1: 2$ & 25 & 12.3 & 90 & 99 & 6.6 \\
\hline $1: 2$ & 35 & 12.3 & 60 & 99 & 6.5 \\
\hline $1: 2$ & 60 & 12.4 & 45 & 99 & 6.0 \\
\hline \multirow[t]{2}{*}{$1: 2$} & 45 & 12.4 & 30 & 99 & 5.6 \\
\hline & $70^{a}$ & & 60 in total $^{\circ}$ & & 1.1 \\
\hline
\end{tabular}

${ }^{a} 30 \mathrm{~min}$ of the reaction at $45^{\circ} \mathrm{C}$ and then 30 min of mixing at $70^{\circ} \mathrm{C}$.

excess of perdecanoic acid at the temperatures in the range of 25 to $60{ }^{\circ} \mathrm{C}$ the post-reaction peroxy group content was almost on the same level till $45{ }^{\circ} \mathrm{C}$ and started slightly decrease from $55{ }^{\circ} \mathrm{C}$. It can be the result of initial decomposition of peracid. From DSC data thermal decomposition of perdecanoic acid

Table 5 Oxidation of various ketones to lactones $^{a}$

\begin{tabular}{|c|c|c|c|}
\hline Ketone & Lactone & Time & Yield/\% \\
\hline & & $45 \mathrm{~min}$ & 99 \\
\hline & & $3 \mathrm{~h}$ & 95 \\
\hline & & $\begin{array}{l}1 \mathrm{~h} \\
90 \mathrm{~min}\end{array}$ & $\begin{array}{l}94 \\
97\end{array}$ \\
\hline & $\mathrm{C}_{7} \mathrm{H}_{15}$ & $\begin{array}{l}4 \mathrm{~h} \\
5 \mathrm{~h}\end{array}$ & $\begin{array}{l}94 \\
97\end{array}$ \\
\hline & & $\begin{array}{l}4 \mathrm{~h} \\
5 \mathrm{~h}\end{array}$ & $\begin{array}{l}93 \\
96\end{array}$ \\
\hline & & $\begin{array}{l}4 \mathrm{~h} \\
5 \mathrm{~h}\end{array}$ & $\begin{array}{l}94 \\
96\end{array}$ \\
\hline & & $5 \mathrm{~h}$ & $3 \%$ \\
\hline
\end{tabular}
${ }^{a}$ Reaction conditions: ketone $(0.67 \mathrm{mmol})$, perdecanoic acid $(1.34$
mmol $)$, toluene $(2 \mathrm{~mL}), 35{ }^{\circ} \mathrm{C}, 1200 \mathrm{rpm}$; yield determined on GC. starts at $64.2{ }^{\circ} \mathrm{C}$. Slow decomposition of perdecanoic acid might be useful to controlled removal of unreacted oxidant. An experiment in which after 30 minutes of oxidation of 2-adamantanone at $45{ }^{\circ} \mathrm{C}$, the mixing was continued by another 30 minutes at $70{ }^{\circ} \mathrm{C}$, revealed that only minor quantity of perdecanoic acid was determined in the post-reaction mixture (about $1 \mathrm{wt} \%)$.

Finally, the favourable reaction conditions were applied to demonstrate the robustness of the method (Table 5). The most reactive were cyclobutanone and 2-adamantanone, and full conversion of ketones was reached after $1 \mathrm{~h}$. The oxidation of more resistant cyclohexanones was completed in $5 \mathrm{~h}$ while the norcamphor was converted in $3 \mathrm{~h}$. Cycloheptanone, which is extremely unreactive due to very stable structure, (lack of ring strain) did not undergo oxidation under these conditions.

\section{Conclusions}

Increasingly stringent environmental regulations of industrial processes, mostly with regard to safety, forced the modification of a number of chemical processes, specially oxidation processes. The results discussed above expanded and developed safe oxidants based on medium-chain peracids. The key development was to perform stability tests for several linear peracids $\left(\mathrm{C}_{6}-\mathrm{C}_{12}\right)$, which were used very rarely as oxidants. This work delivered a new knowledge concerning sensitivity of studied peracids to mechanical impulse (shock and friction), as well as electrical (spark) and thermal sensitivity (temperature and heat of decomposition). These fundamental stability studies resulted in the emergence of safe oxidants. Perdecanoic acid was used as oxidant in the Baeyer-Villiger oxidation for the first time. Peracid was demonstrated to be very robust in terms of substrate scope. High yields of lactones (up to 99\%) were obtained after relatively short reaction times ( $45 \mathrm{~min}$ to $5 \mathrm{~h}$ ), at near-ambient temperature $\left(35^{\circ} \mathrm{C}\right)$. Moving onto the continuous flow system could have significantly influenced the efficiency of the process, but such experiments are beyond the scope of this paper. 
In summary, in this work it has been demonstrated how stability studies can underpin rational design of oxidant that in turn lead to a both safer and economically viable process.

\section{Conflicts of interest}

There are no conflicts to declare.

\section{Acknowledgements}

This work was supported by The National Centre for Research and Development, Poland, within INNOCHEM project, financed from the European Union Operational Programme Smart Growth (No. POIR.01.02.00-00-00042/16).

\section{Notes and references}

1 A. Patnaik, A Comprehensive Guide to the Hazardous Properties of Chemical Substances, John Wiley \& Sons, Inc., 3rd edn, 2007, p. 127.

2 J. Sanchez and T. N. Myers, Peroxides and Peroxide Compounds, Organic Peroxides, Kirk-Othmer Encyclopedia of Chemical Technology, 2000.

3 V. F. Man, K. G. Lascotte, Y. M. Killeen and S. E. Lentsch, Patent WO2010049892A2, 2010.
4 H. Klenk, P. H. Götz, R. Siegmeier and W. Mayr, Peroxy Compounds Organic, Ullmann's Encyclopedia of Industrial Chemistry, 2000.

5 T. Luukkonen and S. O. Pehkonen, Crit. Rev. Environ. Sci. Technol., 2017, 47, 1.

6 M. Renz and B. Meunier, Eur. J. Org. Chem., 1999, 737.

7 K. Yakabi, T. Mathieux, K. Milne, E. M. López-Vidal, A. Buchard and C. Hammond, ChemSusChem, 2017, 10, 3652.

8 M. A. Woodruff and D. W. Hutmacher, Prog. Polym. Sci., 2010, 35, 1217.

9 D. McGinty, J. Scognamiglio, C. S. Letizia and A. M. Api, Food Chem. Toxicol., 2010, 48, 168.

10 C. A. Crampton, C. F. Cardy, K. G. Sampson and I. R. King, US Pat., 3625975, 1971.

11 H. R. Guest and B. W. Kiff, US Pat., 3025306, 1962.

12 M. Markiton, S. Boncel, D. Janas and A. Chrobok, ACS Sustainable Chem. Eng., 2017, 5, 1685.

13 A. Drożdż and A. Chrobok, Chem. Commun., 2016, 52, 1230.

14 V. V. Patil, E. M. Gayakwad and G. S. Shankarling, New J. Chem., 2015, 35, 6677.

15 V. V. Patil and G. S. Shankarling, Beilstein J. Org. Chem., 2014, 10, 921.

16 W. E. Parker, C. Ricciuti, C. L. Ogg and D. Swern, J. Am. Chem. Soc., 1955, 77, 4037.

17 Y. W. Wang, M. S. Liao and C. M. Shu, J. Therm. Anal. Calorim., 2015, 119, 2257. 